\title{
Prospective Study of Communication and Information Technologies for the Deaf
}

\author{
Aline da Cruz Porto Silva ${ }^{1 *}$, Luiz Antonio da Silva Gonçalves ${ }^{2}$ \\ ${ }^{1}$ Federal Institute of Bahia/IFBA; ${ }^{2}$ Federal University of Bahia/UFBA; Salvador, Bahia, Brazil
}

\begin{abstract}
This article presents a prospective study of Information Technologies and Communication for Deaf people. Aims to carry out a technological investigation of patents filed in Questel Orbit, to identify the Accessible Information and Communication Technologies developed for Deaf people. The methodological path in this research is a systematic review, exploratory, and prospective study of technologies. So, we identified ninety-two documents filed in the Orbit patent database. This prospective study showed a progressive growth of papers in the last five years, but discreet regarding developed Deaf technologies' registration. It also highlights that China has the highest number of these technologies, while Brazil has only one technology developed.

Keywords: Prospecting. Technology. Communication. Deaf. Patent.
\end{abstract}

\section{Introduction}

The development of Information and Communication Technologies (ICT) enables an education space, providing opportunities to develop new spaces of teaching and learning. Digital innovations place informational resources and communication tools more accessible to users, helping people use the available tools.

The development of an 'interface' accessible to people with disabilities promotes digital inclusion and enables knowledge. In this study, we chose hearing loss /Deafness.

According to Marchesi (1996) [1], deafness is characterized by loss, larger or minor, of the current perception of sounds, with several categories of hearing impairment, in general, classified according to the degree of hearing loss.

Currently, the expression deaf is used, in the clinical/medical context, to the person who has a hearing deficit that impedes acquiring the oral/ auditory language. However, the term Deaf is used especially by the deaf community to build a cultural identity anchored in the Brazilian Sign

Received on 22 June 2021; revised 27 October 2021.

Address for correspondence: Aline da Cruz Porto Silva. Rua Doutor Gerino de Souza Filho. No. 2864, Edificio Paul Cézanne, 401 Lauro de Freitas / Bahia. E-mail: linelibras@, gmail.com.

J Bioeng. Tech. Appl. Health

2021;4(4):147-151

(C) 2021 by SENAI CIMATEC. All rights reserved.
Language - Libras recognized and regulated by laws and federal decree.

According to Skliar (1999 p.142) [2], sign language cancels the deficiency and allows that the deaf constitutes, then, a different minority linguistic community and not a deviation from "normality". So, thinking of deafness should be as a linguistic difference, not a pathology nor a disability that attributes to the Deaf person a condition of inferiority for being users of a modality of language visual-gesture.

In this sense, the present study aimed to survey world technology of patents filed in Questel Orbit ${ }^{\circledR}$, thus intending to identify the accessible Information and Communication Technologies developed for Deaf people.

Information and Communication Technology $\mathrm{x}$ Importance of ICTs

In modernity with the Internet Invention and current evolution, the information reaches people quickly and, the use of various tools provides, above all, interaction and consequently learning. According to Levy (1999) [3], new ways of thinking and living are being developed in the world of Computing. Thus, various technological resources have been created to contribute to human life beings, which we highlight as one of the most Eminent Information and Communication Technologies (ICT's).

ICTs are made up of technical resources integrated with some objectives and as a tool that 
allows communication between humans without barriers. Consequently, through the 'internet', information and communication systems are developed, forming a network that is constantly reinventing itself. For Vasconcelos (2015) [4], technologies should contribute to personal experiences, sensations and create emotions regardless of culture and location, enabling new experiences through networks that allow access to information.

In this manner, information and communication technologies, as tools, create different spaces for interaction, teaching, and learning, providing autonomy, making information and communication accessible to everyone in the democratic process of contemporary society.

TheImportance ofInformationandCommunication Technology for the Deaf

Information and Communication Technology play a pivotal role in the digital and social inclusion of the Deaf, as it helps with information and communication.

For Rosa and Cruz (2001) [5], the Internet and its various configurations are crucial for the insertion of the Deaf in society, because it provides a multiplicity and diversity of visual resources, enabling a better understanding of the messages since their communication takes place through the Brazilian Sign Language, which constitutes a visual-space language. ICTs contribute by capacitating the Deaf to have access to information, communication, and consequently to knowledge.

\section{Materials and Methods}

We did a literature review, followed by a prospective study of technological solutions with potential application in deaf education. A survey of patent application processes was carried out on the Questel Orbit Intelligence ${ }^{\circledR}$ software platform, filed nationally and internationally in the period 2001 to 2021.
Questel Orbit Intelligence ${ }^{\circledR}$ was chosen because it enables statistical analysis and the generation of graphs and maps on broad sets of patents, filing companies, inventors, geographic distribution, legal status, and year of registration.

Questel Orbit ${ }^{\circledR}$ is a paid platform for online access to the patent search and analysis system with information on more than 107 million patents filed in several countries [6]. The search strategy used was the advanced search - Title, Abstract, and Claims - for the following descriptors in English — Technology, Communication, Deaf. The logical Boolean operator "and" was also used to cover a more effective result, as shown in Figure 1. Data collection was carried out in July 2021.

The inclusion and exclusion criteria were the Information and Communication Technologies developed for the Deaf, deposited in the Questel Orbit database since 2002 - the year of Law 10.436 that regulates the Brazilian Sign Language. The exclusion criteria were patents that did not focus on the researched subject and those filed before Law 10.436 of April 24, 2002 [7,8].

\section{Results and Discussion}

We selected and analyzed 92 patent documents focusing on the study of Information and Communication Technologies developed for the Deaf, deposited in the Questel Orbit database (2021) [6]. The results present the distribution of patents among countries; the annual evolution of patent filings over the years; the identification of the 15 biggest assignees of the 15 biggest inventors.

Figure 2 shows the world map of countries with Information and Communication Technologies developed for the Deaf. The gray color means countries without patents, and as the blue color gets darker, it means increasing the number of patents.

Assessing the documents obtained through technological prospecting, it was possible to observe that the largest developing country of information and communication technologies 
Figure 1. Data collection (July 2021).

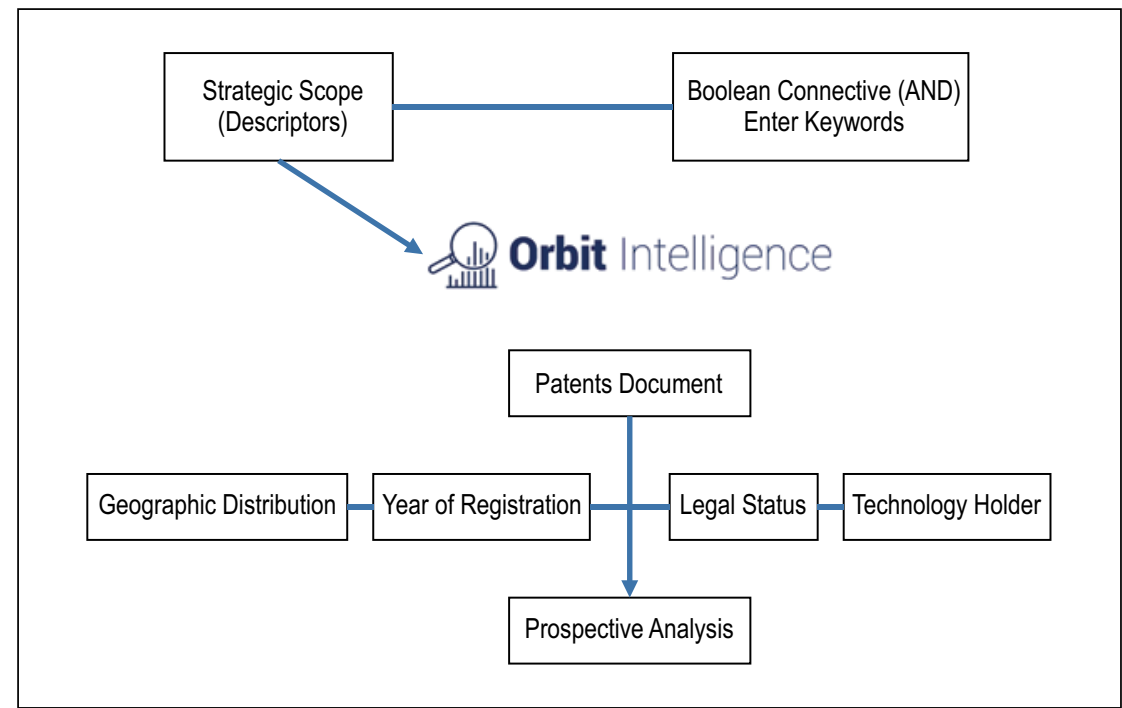

Source: Adapted from Gonçalves and Bezerra (2018) [9].

Figure 2. Distribution of patents between countries.

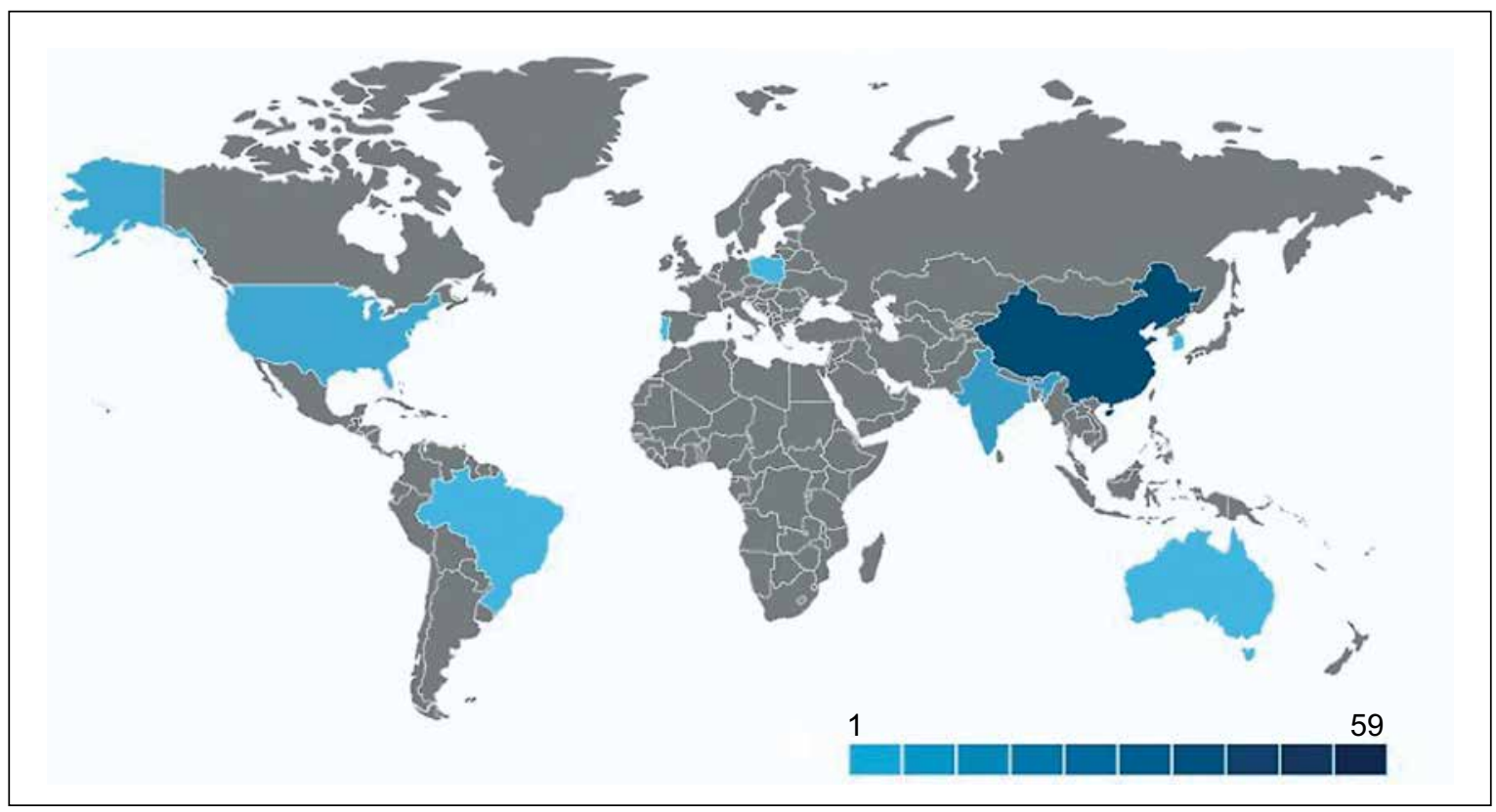

Source: Questel Orbit (2021) [6].

developed for the Deaf is China with 59 patents, followed by India with 16 and the United States with 11 technology.

Figure 3 shows the annual evolution of patent applications filed, correlated in the various technological areas, between the years 2002 to 2021. We observed that the number of registered patents remains constant from 2008 to 2015 . However, there was a pattern of growth, with some atypical peaks in the years 2016 to 2020, after then there was a sharp drop in the number of publications. The year 2018 had a high occurrence in patent registrations with 22 filings. 
The year 2021 should not be interpreted as a result of low investments in research and development, based on the number of patents filed in the area, noting that the reduced number must be explained by the period of secrecy, which normally lasts 18 months.

In Figure 4, it is possible to verify the relationship between the Institutions with the prominence in the protection of information and communication technologies developed for the Deaf and the number of patents related to each one of them. So, Chinese universities appear with a significant percentage of deposits, as it confirms the predominance of university institutions.

In Figure 5, the top 15 inventors are listed in a 20-year interval based on the priority year, highlighting inventors Ceng Yaokuan, Li Guanghuang, Li Wanjian, Luo Hui, Qin Guomi, Zhong Zhiwei, and Zhu Penghui, all of them with 03 families of patents.

The results presented in this prospective study show that after the enactment of Law 10.436 24/04/2002 [7], which recognizes Libras as the first language of Deaf people, in Brazil the advances in the development of new assistive technologies for Deaf people who communicate in the Language of signs are still incipient about other inventor countries.

\section{Final Considerations}

This prospective study made it possible to consider that there are patented technologies around the world on information and communication technology for the Deaf. With the search, it was possible to observe that Brazil has one (01) registered technology. Our study shows that Brazil has not given importance to the development of assistive technologies which would provide the Deaf with access to information and communication, ensuring digital and linguistic accessibility, according to Brazilian legislation. On the opposite way to Brazil, we observed that countries such as China, India, and the United States of America intensify studies in large University Institutions.

Therefore, we verified that the registration of patents is an indicator of the development of information and communication technology for the Deaf, in this manner, it presented a gradual growth in the last five years, although still discreet registration.

The use of technologies is essential for social inclusion and enables people's cognitive development. In the digital age, several technologies have been helped the Deaf, especially in communication, and provided social inclusion.

Figure 3. Annual evolution of patent filing over the years.

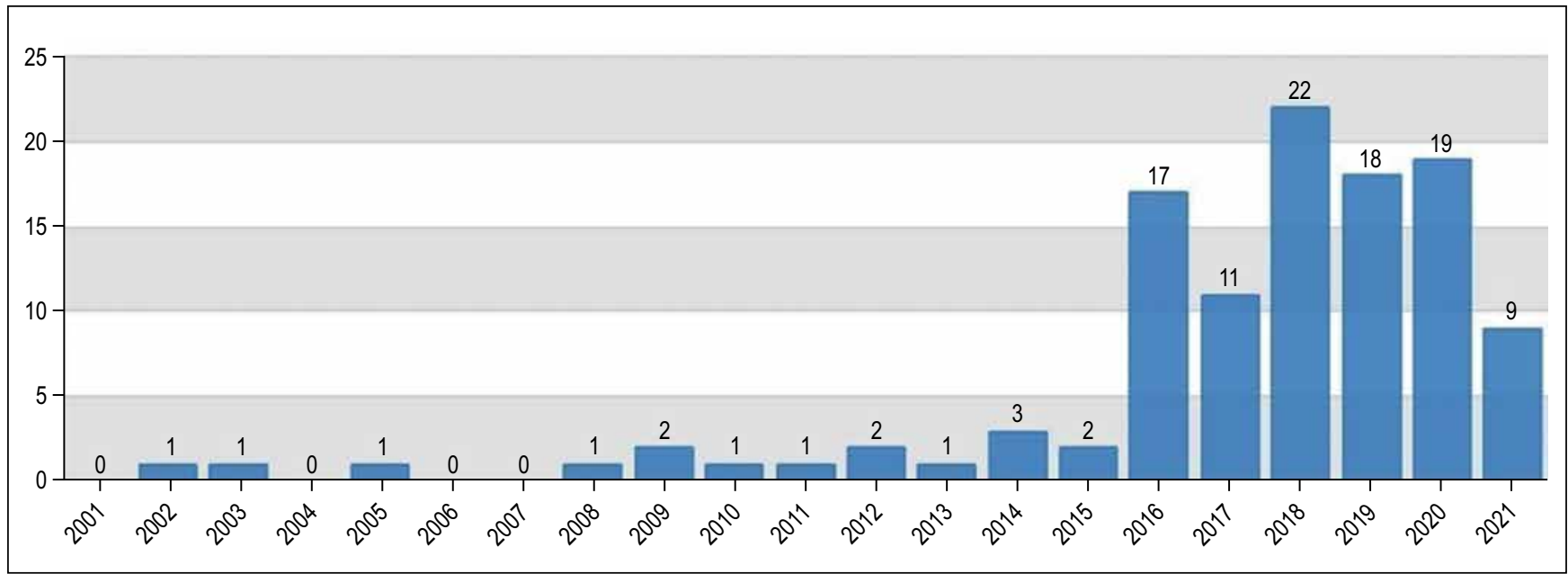


Figure 4. Identification of the 15 largest technology holders.

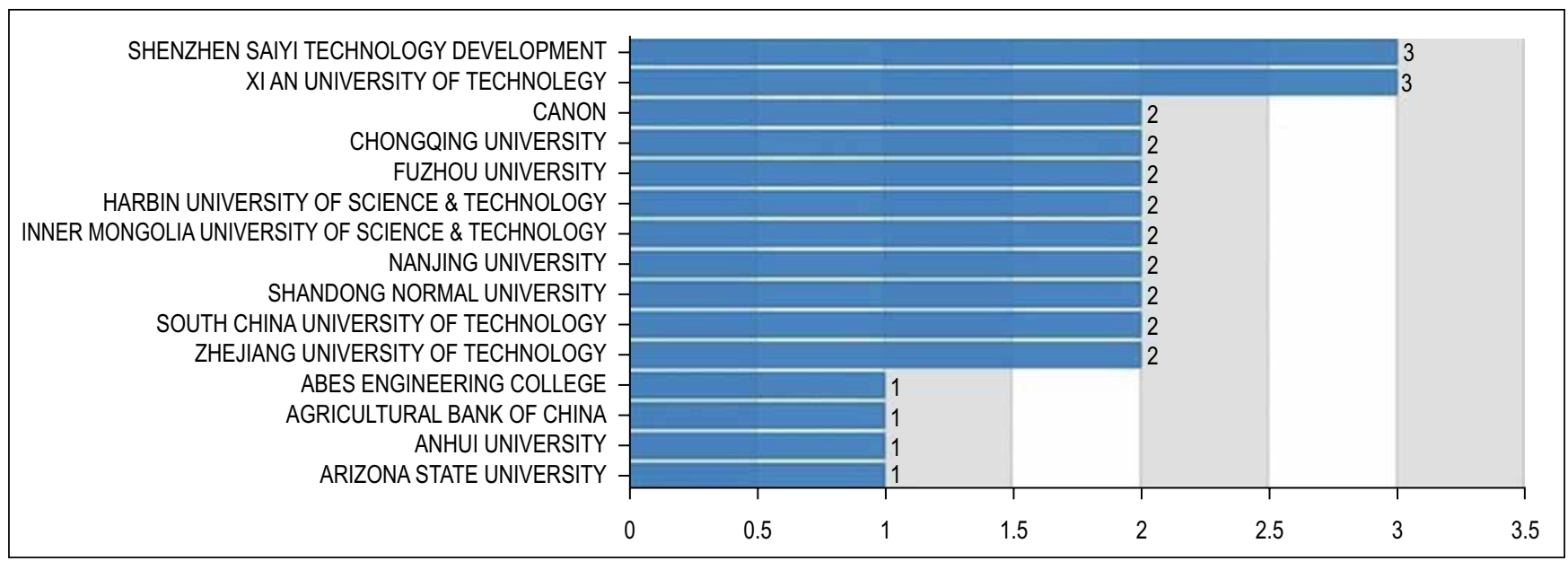

Figure 5. Identification of the 15 greatest inventors.

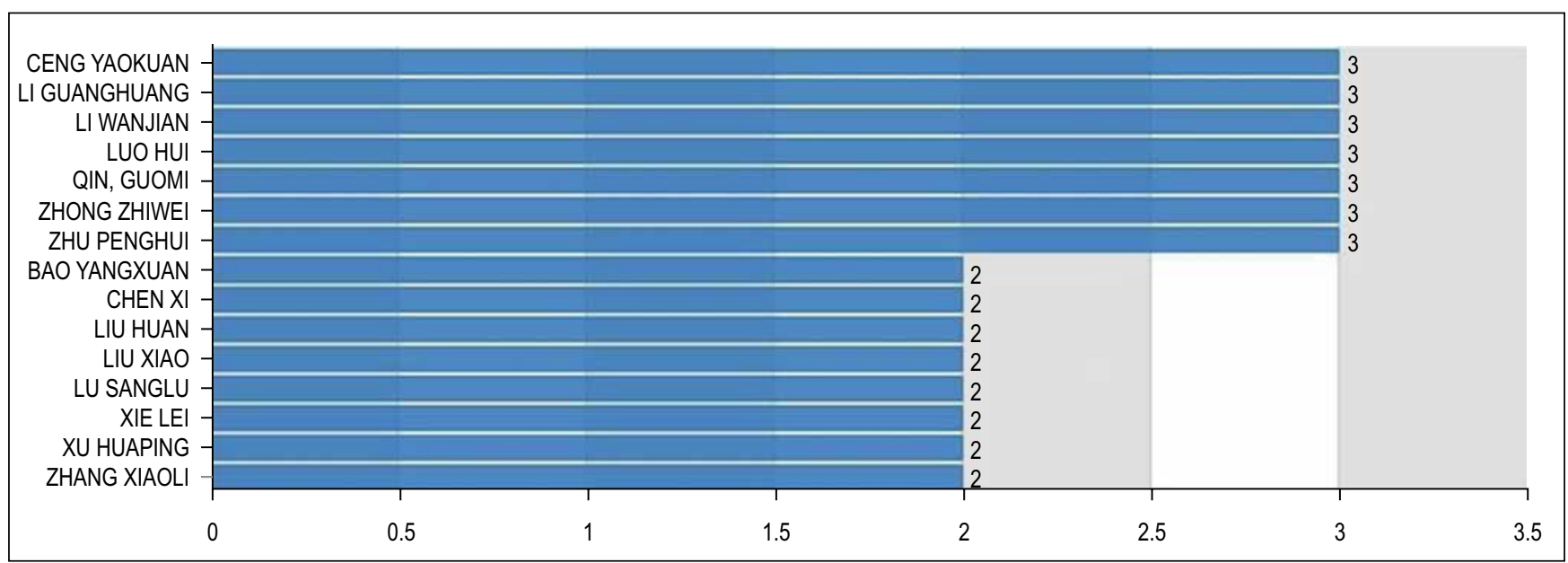

\section{References}

1. Marchesi, A. (1996). Communication, language, and thinking. In César Call; Jesus Palaces \& Álvaro Marchesi. (Org.), Psychological Development and Education. Porto Alegre: Medical Arts, 1996: 200-216.

2. Skliar C. Deafness: a look at the differences. Porto Alegre: Mediation, 1998.

3. Lévy P. Cyberculture. São Paulo: Editor 34, 1999.

4. Vasconcelos CA. Interactive interfaces in the undergraduate course in geography at UAB at IFPE and UFS. 2015. 109f. Report (Post-Doctoral Internship) Postgraduate Program in Contemporary Education. Federal University of Pernambuco, Caruaru, PE, 2015.

5. Rosa AS, Cruz CC. Internet inclusion factor of the deaf person. Campinas, Rev. Online of the Library. Prof. Joel Martins 2001;(2)3:38-54.
6. Questel Orbit IP Business Intelligence. [2021]. Available at: https://www.questel.com/software/ipbi/. Accessed on: Oct 4th. 2021.

7. Brazil. Law 10.436 of April 24, 2002. Available at: http://www.planalto.gov.br/ccivil_03/leis/2002/ 110436.htm. Accessed on August 08, $202 \overline{1}$.

8. Decree No. 5.626, of December 22, 2005. Regulates Law No. 10.436, of April 24, 2002, which provides for the Brazilian Sign Language - Libras, and art. 18 of Law No. 10,098, of December 19, 2000. Official Gazette of the Union.

9. Gonçalves LAS, Bezerra JS. Prospective study of the technological process of pyrolysis with emphasis on INPI's green patent program. Prospecting Notebook. Salvador, v. 11, no. 1, p.74-86, Jan./Mar.2018 Official Gazette: http://dx.doi.org/109771/cp.v11i1.23094. 